\title{
INVESTIGATIONS OF E.E.G. FINDINGS IN PRESENILE DEMENTIA
}

\author{
BY \\ D. W. LIDDELL \\ From Runwell Hospital, near Wickford, Essex
}

The diagnosis of presenile dementia is used in its widest sense. Clinically, it is impossible to distinguish between the various neuropathological subgroups that make up this group of dementias. The exact diagnosis is only ascertained at death, although biopsies may be diagnostically useful.

There appears to be considerable doubt about the E.E.G. findings in this group of patients. Hill (1948), in 16 cases of presenile cortical atrophy, found an abnormal E.E.G. in eight and a severely abnormal E.E.G. in four. This abnormality appears to have been local delta and slowed alpha at 6 to $8 \mathrm{c}$./ $/ \mathrm{sec}$. Green, Stevenson, Fonseca, and Wortis (1952) divided a series of presenile dementias into cases of Alzheimer's disease and those not of Alzheimer's disease on the basis of cortical biopsies. They concluded that there was no specific E.E.G. pattern in Alzheimer's disease. In five out of seven of their cases, slowing of the alpha rhythm and very slow irregular delta waves were present. The delta wave activity was diffuse but most marked in the temporal and posterior parietal regions, often on one side more than the other. On the other hand, eight cases of presenile dementia which were not Alzheimer's disease showed slowing of the alpha rhythm associated with focal abnormalities, consisting of voltage depressions or paroxysmal activity, not confined to any particular area. Mundy-Castle, Hurst, Beerstecher, and Prinsloo (1954) found only one abnormal E.E.G. in a series of 10 presenile dementias. However, in his senile psychotic group diffuse delta and theta rhythms were observed and occurred most often in the most severely demented cases.

\section{Material and Method}

In view of this uncertainty, it was determined to investigate the E.E.G. findings of the patients suffering from presenile dementia in this hospital. All cases of organic dementia below an arbitrary age of 70 years were selected for investigation, and it was then found that 11 patients fell into this group. The diagnosis was made on clinical grounds and the atrophy was confirmed by air encephalography. In addition, three of the patients have since died and have been investigated pathologically, confirming the clinical diagnosis of Alzheimer's disease, From the clinical point of view these cases showed an insidiously progressive course of deterioration, involving the social, intellectual, and emotional components of the personality. Eventually they arrived at a state of severe dementia in which dysphasic and dyspraxic symptoms dominated. A number of these patients at some time or another had attacks of momentary loss of consciousness. These attacks, however, were very infrequent. In all these cases the Wassermann reaction was negative and there was no gross cardiovascular disease. It is important to stress that the onset and progress of the illness was smoothly continuous and in no way episodic like a further group of dementias associated with vascular disease. Similarly, such nosological entities as Huntington's chorea were excluded.

This group of cases of presenile dementia consisted of two men and nine women with an average age of 60 years, ranging from 51 to 66 years. In most cases the degree of dementia was so severe that they were incapable of being tested by routine psychological tests. The E.E.G.s were taken with an Ediswan six-channel machine.

\section{Results}

The findings in all cases were similar. The records showed a generalized basic rhythm of diffuse medium amplitude theta or slow alpha activity at 6 to $8 \mathrm{c}$. $/ \mathrm{sec}$. Superimposed on this basic activity, paroxysmal bursts of synchronous high-amplitude delta waves occurred. These bursts had a tendency to repeat themselves rhythmically and were of greatest amplitude in the frontal and temporal regions (Figs. 1 and 2). For long periods this paroxysmal activity was absent and during these times the basic activity changed. It now showed a polyrhythmic pattern composed of medium-voltage mixed delta and theta wave activity. The background activities, as well as the paroxysmal bursts, were temporarily inhibited when the patient's attention was aroused by visual or auditory stimuli. At these 

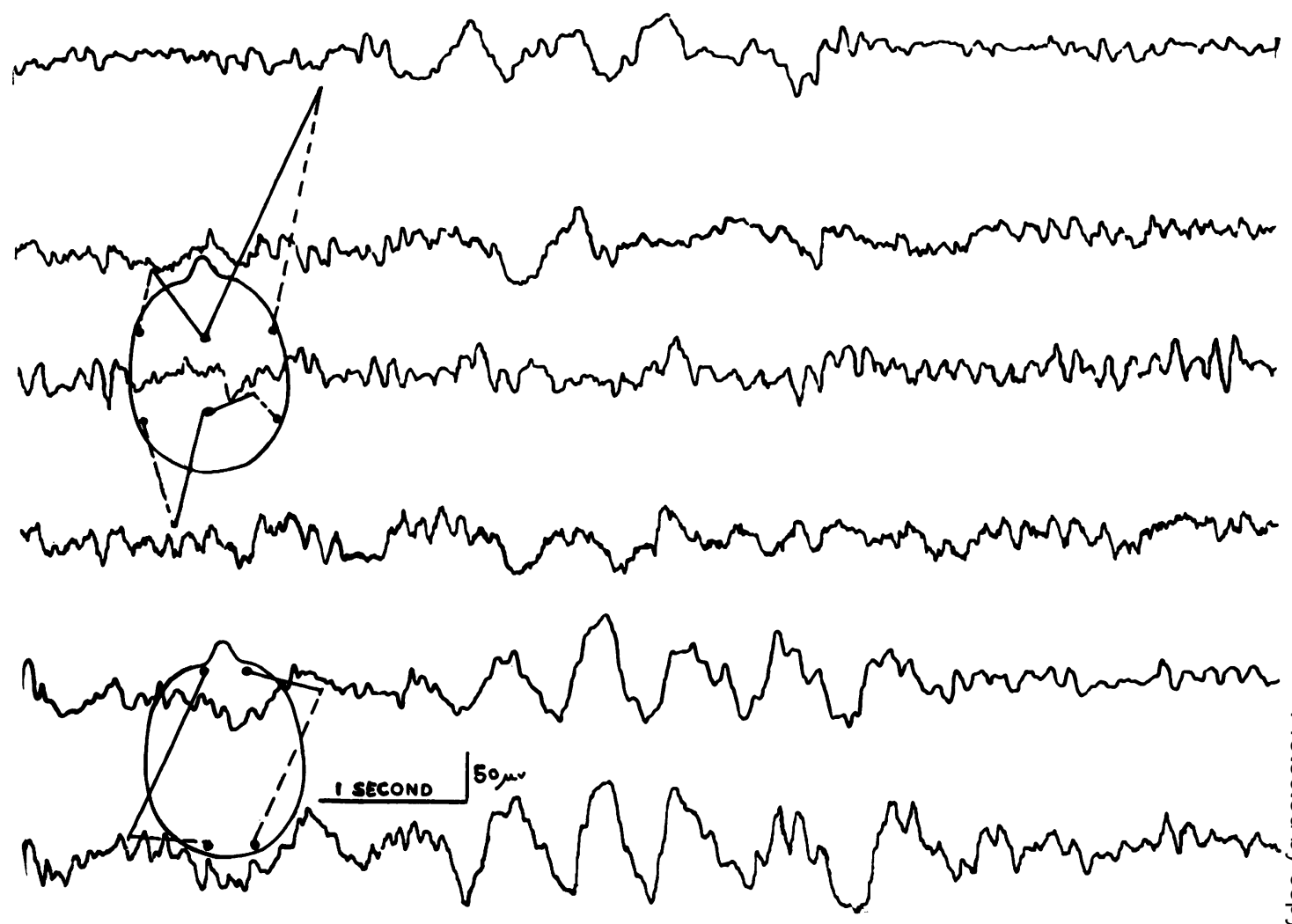

Fig. 1.-Repetitive delta bursts occurring on a background of mixed theta and slow alpha waves.

times an alpha rhythm appeared in most cases. However, even if the eyes remained open, the basic slow activity soon replaced the alpha wave activity. The appearance of the alpha wave activity also occurred spontaneously, breaking through the basic pattern of slower activity (Fig. 3). It was felt that this emergence of alpha activity was possibly related to visceral afferent impulses arriving at the cortex and temporarily holding the patient's attention, as no obvious external stimuli were discernible. When these patients were subjected to photic stimulation the electrical cortical activity followed at the same frequency.

This type of record bore a resemblance to light sleep with spontaneous $\mathrm{K}$ complexes, with, however, no sleep spindles. However, when sleep was induced with "pentothal" or " seconal" the record flattened, the paroxysmal delta activity was abolished, and later high-amplitude, irregular, very slow delta waves dominated, with $10 \mathrm{c}$./sec. spindles frontally. At no time could $\mathrm{K}$ complexes be elicited. The fast activity reduced by barbiturates was absent, as Pampiglione (1952) showed in cases of cortical atrophy.
If presenile dementia is but a form of early ageing rather than a specific pathological process, then such a type of record should be common among the senile population of this hospital. Again, it might be argued that the traces are not specific and were related only to apathy and dementia per se. For this purpose, 100 patients, whose ages ranged from 70 to 85 years, were subjected to an E.E.G. investigation. These patients often showed a considerable degree of organic deterioration, mostly due to cerebral vascular disease. In this group of 100 senile patients, only seven patients (two men and five women) showed a trace similar to that in the group of patients with Alzheimer's disease. Clinical examination of these patients showed a profound degree of dementia of many years' duration, starting before the age of 70 years. They were thought to be closely related cases, if not actual cases, of Alzheimer's disease of relatively late onset. In fact, one patient has since died and necropsy findings were pathologically indistinguishable from those of Alzheimer's disease. Of clinical interest, in passing, it would appear that the earlier the onset of symptoms in presenile dementia, the more rapid is the 



Fig. 2.-Spontaneous delta paroxysm occurring on a slow alpha 6 to $8 \mathrm{c}$./sec. background.

clinical course of the illness, and conversely, those patients whose symptoms develop later in life run a more slowly progressive course.

It is now generally accepted that it is impossible to distinguish pathologically between Alzheimer's disease and senile dementia, as both are characterized by neurofibrillary tangles and senile plaques. Electroencephalographically, these two groups of presenile and senile dementia also appear to be similar. The E.E.G. findings then suggest that the pathology is specific and in no way connected with the process of normal ageing or simply to dementia, as equally severe cases of dementia due to vascular disease did not show this type of tracing.

These types of record appear to be related to the lowered awareness which these patients show clinically. Under the influence of afferent stimuli, such as photic stimulation, the cortex is temporarily able to behave in an electrically normal manner, in spite of the presence of gross cortical atrophy. This suggests that there are sufficient cortical cells remaining in these patients to respond in an electrically normal manner under stimulating conditions. However, in the absence of this added specific stimulation, such normal activity is not recorded, except temporarily when patients first open their eyes and this in itself is a strong afferent stimulation. Instead, a pattern of rhythmically occurring delta waves superimposed on a slow background of theta wave activity was obtained. The response to photic stimulation suggests that the origin of the abnormal E.E.G. is not cortical and, therefore, appears to arise from deeper structures. By analogy, is this so, as the delta bursts are bilaterally synchronous and arise frontally, for a similar localization is seen in spikeand-wave discharge and in normal $\mathbf{K}$ complexes. In these conditions the origin of these waves is thought to be from deep midline nuclei.

In view of the severe cortical atrophy, this response might be considered in the nature of a release of deep midline nuclei from cortical control. This suggestion is further strengthened by the resemblance of these records to those obtained in sleep, in which cortical function is inhibited. Clinically, this paroxysmal activity may well be related to the occasional lapses of consciousness that these patients sometimes show.

The findings in our series suggest that in presenile dementia the E.E.G. is grossly disturbed. The traces are probably similar to those of Hill (1948) and Green et al. (1952). While the abnormality is not specific for an exact pathological diagnosis, it is 


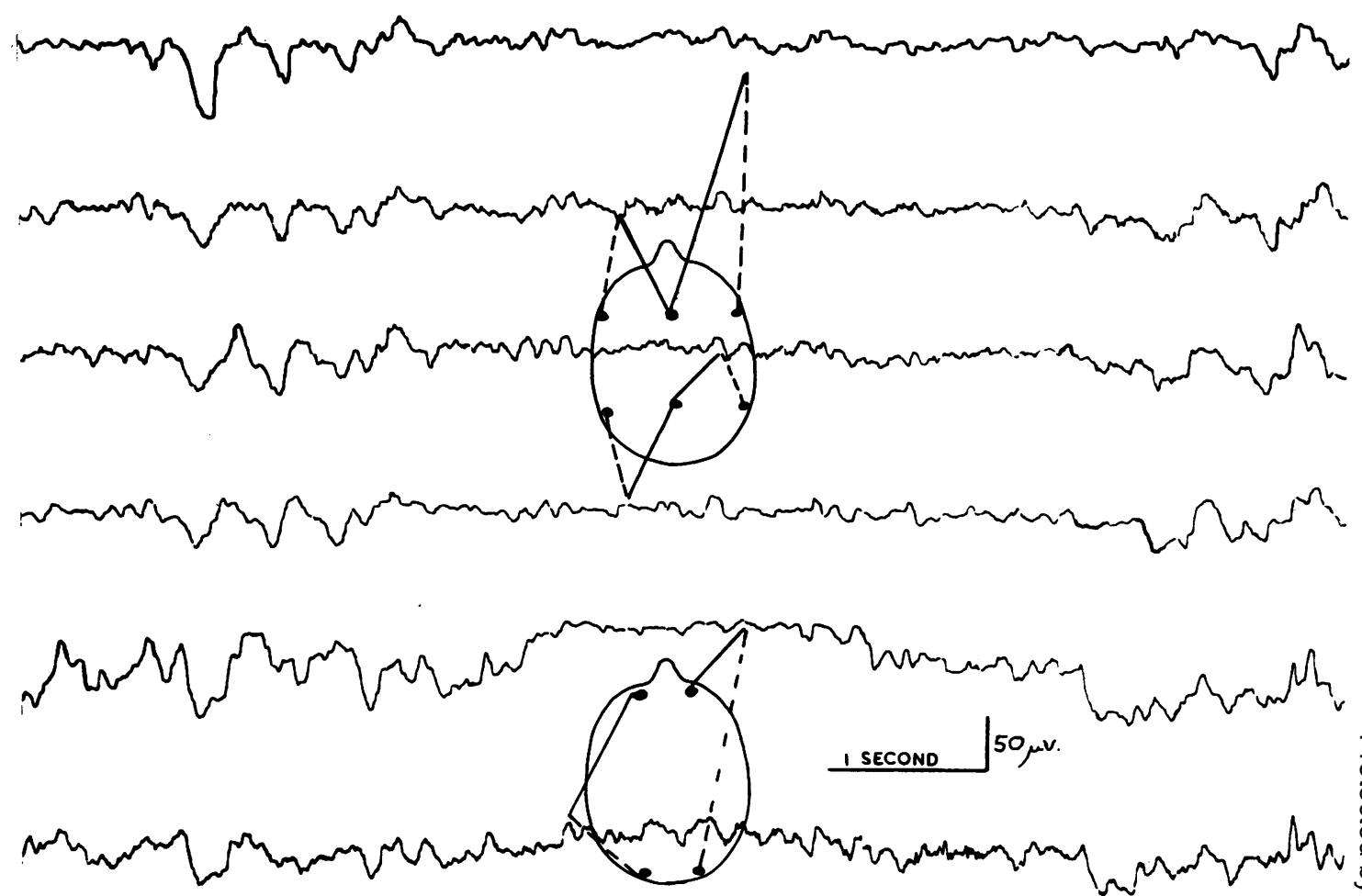

FIG. 3.-Mixed delta and theta activity with a larval anterior delta burst, showing sudden spontaneous appearance of normal alpha wave activity.

sufficiently recognizable and striking to suggest at once the diagnosis of severe dementia due to cortical atrophy of Alzheimer type.

\section{Summary}

Electroencephalographic examinations were carried out on 18 cases of severe dementia, consisting of 11 cases occurring during the presenile period and seven cases during the senile period, and all showing classical symptoms of Alzheimer's disease.

The records were grossly abnormal and were sufficiently unusual to be a useful aid in the diag- nosis of dementia due to cortical atrophy of the Alzheimer type.

The sex ratio of these 18 patients is four male to 14 female patients but the number is too small to be definite about a sex difference in Alzheimer's disease.

\section{REFERENCES}

Green, M. A., Stevenson, L. D., Fonseca, J. E., and Wortis, S. B. Green, M. A.,, Stevenson, L. D., Fonseca

Hill, D. (1948). Proc. roy. Soc., Med., 41, 242.

Mundy-Castle, A. C., Hurst, L. A., Beerstecher, D. M., and Prinsloo, T. (1954). Electroenceph. clin. Neurophysiol., 6, 245.

Pampiglione, G. (1952). Ibid., 4, 79. 
The Facts of Mental Health and Illness. New (2nd) edition fully revised. By K. R. Stallworthy. (Pp. 218. 22s. 6d. New Zealand price.) Christchurch, N.Z.: N. M. Peryer. 1958.

Amphetamine Psychosis (Maudsley Monographs No. 5). By P. H. Connell. (Pp. 133. 21s.) London: Chapman \& Hall. 1958.

Thudichum-Chemist of the Brain. By David L. Drabkin. (Pp. 309; 52 figures. 40s.) London: Oxford University Press. 1958.

A Primer of Cerebral Palsy. By Joseph D. Russ and Hyman R. Soboloff. (Pp. viii $+77 ; 16$ figures. 30s.) Oxford: Blackwell Scientific Publications; Springfield, Illinois: Charles C. Thomas. 1958.

Ein binauraler Hörsynthese-Test zum Nachweis zerebraler Hörstörungen. By J. Matzker; Foreword by H. Leicher. (Pp. $x+117$; 46 figures. DM 19.80.) Stuttgart: Georg Thieme. 1958.

A Ciba Foundation Symposium on the Neurological Basis of Behaviour in commemoration of Sir Charles Sherrington, O.M., G.B.E., F.R.S., 1857-1952. Edited by G. E. W. Wolstenholme and Cecilia M. O'Connor. (Pp. xii +400 ; illustrated. 52s. 6d.) London: J. \& A. Churchill. 1958.

Le Syndrome Tétanie. By Th. Alajouanine, F. Contamin, and H. P. Cathala. (Pp. 279; 29 figures.) Paris: J. B. Baillière 1958.

La Physiologie et la Physiopathologie du Cervelet. By A. Kreindler and M. Steriade; Foreword by P. Mollaret. (Pp. 308; 87 figures. Fr. fr. 3,200.-.) Paris: Masson. 1958.

Le Syndrome de Guillain-Barré et les polyradiculonévrites aiguës avec dissociation albumino-cytologique dans la liquide céphalorachidien. By $\mathbf{R}$. Coirault, A. Larcan, and P. Davidou; Foreword by P. Garcin. (Pp. 200. Fr. fr. 2,000.-.) Paris: Masson. 1958.

Psychotherapy by Reciprocal Inhibition. By Joseph Wolpe. (Pp. xiv + 239. 40s.) London: Oxford University Press. 1958.

Thérapeutique Neurologique et Psychiatrique, 2nd edition entirely revised. By Paul Cossa in collaboration with H. Bougeant, J. Boudouresques, J. Duplay, E. Le Coq, J. Postel, and R. Rivoire. (Pp. 610. Fr. fr. 4,800.-; bound 5,800.-.) Paris: Masson. 1958.

Theory of Psycho-Analytic Technique. By Karl A. Menninger. (25s.) London: Imago Publishing Co. 1958.

Diagnostica Psichiatrica, Parte Speciale. By Agostino Rubino; Foreword by Prof. V. H. Buscaino. (Pp. xiv + 443; 99 figures. L. 5,500.-.) Naples: Libraria V. Idelson. 1958.

Psychopathic Personalities, 9th ed. By Kurt Schneider (translated by M. W. Hamilton); Foreword by E. W. Anderson. (Pp. xiv + 163. 18s.) London: Cassell. 1958.

Die beginnende Schizophrenie. By K. Conrad. (Pp. viii +165. DM 19.80.) Stuttgart: Georg Thieme. 1958.

The Waking Brain. By H. W. Magoun. (Pp. viii +138 ; 55 figures. 36s.) Oxford: Blackwell Scientific Publications; Springfield, Illinois: Charles C. Thomas. 1958.
Clinical Neuroanatomy, Neurophysiology and Neurology: with a Method of Brain Reconstruction. By Louis Hausman. (Pp. xxv +522; 9 plates. 73s. 6d.) Oxford: Blackwell Scientific Publications; Springfield, Illinois: Charles C. Thomas. 1958.

Differentialdiagnose Neurologischer Krankheitsbilder. Edited by G. Bodechtel. (Pp. xxviii + 975; 533 figures. DM 120.-.) Stuttgart: Georg Thieme. 1958.

The Physical Foundation of Biology. By Walter $\mathbf{M}$. Elasser. (Pp. 219; 16 figures. 30s.) London: Pergamon Press. 1958.

The Brain and Human Behaviour. Proceedings of the Association for Research in Nervous and Mental Disease, Vol. XXXVI. Edited by Harry C. Solomon, Stanley Cobb, and Wilder Penfield. (Pp. xi+564; illustrated. 120s.) London: Baillière, Tindall Cox. 1958.

Clinical Examination of the Nervous System, 11th ed. By G. H. Monrad-Krohn. (Pp. xx+466; 173 figures. 40s.) London: H. K. Lewis. 1958.

L'Hypophysectomie dans le Traitement du Cancer. By J. Le Beau; Foreword by Prof. Marcel Perrault. (Pp. 126; 17 figures. Fr. frs. 1,800.-.) Paris: G. Doin. 1958.

Psychopharmacology: Pharmacologic Effects on Behaviour. Edited by Harry H. Pennes. (Pp. xiv +362 ; 35 figures. 60s.) London: Cassell. 1958.

The Psychiatric Hospital as a Small Society. By William Caudell. (Pp. xxiii + 406; illustrated. 52s.) Harvard University Press (London: Oxford University Press.) 1958.

Diseases of the Nervous System, 9th ed. By Sir Francis Walshe. (Pp. xvi+373; 58 figures. 30s.) Edinburgh and London: E. \& S. Livingstone. 1958.

Cure de Sommeil Collective et Psychothérapie de Groupe. By Henri Faure; Foreword by Prof. Henri Ey. (Pp. 272; 5 figures. Fr. fr. 2,500.-.) Paris: Masson. 1958.

Head Injuries. Compiled by E. S. Gurdjian and J. E. Webster. (Pp. 482; \$14.-.) Boston: Little, Brown \& Company. 1958.

Correction. In the paper "Investigations of E.E.G. Findings in Presenile Dementia ", published in August, 1958, (J. Neurol. Neurosurg. Psychiat., 21, 173) we regret that the descriptions of records (Figs. 2 and 3) have been interchanged.

Foundations' Fund for Research in Psychiatry

The next deadline for the submission of completed applications for research fellowships in psychiatry, psychology, sociology, neurophysiology, and other sciences relevant to mental health is January 15, 1959.

The next deadline for receipt of applications for research grants-in-aid is December 10, 1958. Interested persons are invited to write for details to: Foundations' Fund for Research in Psychiatry, 251 Edwards Street, New Haven 11, Connecticut. 